\section{$\underset{\substack{\text { hommes } \\ \text { \& migrations }}}{ }$}

\section{Hommes \& migrations}

Revue française de référence sur les dynamiques

migratoires

$1309 \mid 2015$

Le $3 e$ âge des migrants

\title{
Hanan el-Cheikh, La Maison de Schéhérazade
}

Traduit de l'arabe (Liban), Stéphanie Dujols, Actes Sud/Sindbad, 2014, 380 pages, $23 €$

\section{Mustapha Harzoune}

\section{OpenEdition}

\section{Journals}

Édition électronique

URL : http://journals.openedition.org/hommesmigrations/3129

DOI : 10.4000/hommesmigrations.3129

ISSN : 2262-3353

Éditeur

Musée national de l'histoire de l'immigration

Édition imprimée

Date de publication : 1 janvier 2015

Pagination : 210

ISBN : 978-2-919040-30-8

ISSN : $1142-852 X$

Référence électronique

Mustapha Harzoune, " Hanan el-Cheikh, La Maison de Schéhérazade», Hommes \& migrations [En ligne], 1309 | 2015, mis en ligne le 22 juillet 2015, consulté le 24 septembre 2020. URL : http://

journals.openedition.org/hommesmigrations/3129; DOI : https://doi.org/10.4000/

hommesmigrations.3129 


\section{LIVRES}

\section{Hanan el-Cheikh}

La Maison

de Schéhérazade

Traduit de l'arabe (Liban) parStéphanie Dujols, Actes Sud/Sindbad, 2014. 380 pages, $23 €$

"- Comme j'aimerais que tu te rases la barbe et que ton visage soit lisse comme une prune...

Aussi irrité par ce qu'il vient d'entendre qu'émoustillé par ses caresses, Baqbouq objecta :

- Si je me rase la barbe, tout le monde se moquera de moi au marché. Non, non, je ne veux pas faire ça!

Mais, attrapant sa main, la femme lui fit toucher son visage.

- Sens-tu comme ma peau est délicate? Ne dirait-on pas un pétale de fleur? Elle est si sensible qu'une petite brise l'éraflerait."

Dans Le Monde du 19 janvier 2015, l'écrivain Abdellah Taïa interroge : "Pourquoi un peuple qui a fait [des Mille et Une Nuits] le rival du Coran se comporte-t-il comme s'il ne l'avait pas lu ?" Hanan elCheikh partage, semble-t-il, le questionnement de son jeune confrère.

La romancière libanaise, installée à Londres, propose avec cette Maison de schéhérazade, de relire, via une adaptation pour le théâtre, quelques contes et poèmes extraits de ces Mille et Une Nuits. La sélection fait sens et offre aux lecteurs contemporains - cadeautés il y a peu de la traduction de Jamel Eddine Bencheikh et André Miquel - une adaptation tout à l'honneur des femmes. Puisant dans l'histoire et le patrimoine littéraire de la civilisation musulmane et oui ! Tant pis pour la doxa d'Occident et les barbichettes courroucées d'Orient - Hanan el-Cheikh en extrait des figures de femmes indépendantes, entreprenantes, intelligentes, spirituelles, aimantes, des corps libres, disposés à aimer et à être aimés. La civilisation musulmane - plutôt que l'islam religion - est bien loin ici du triste spectacle offert par quelques contemporains.

Elleest ludique, joyeuse, sensuelle, rafraîchissante et raffinée. On y jouit des corps et des fruits de la vigne. On y savoure aussi le verbe. Le verbe ! Celui d'une femme.Celuidudésiropposéàla loi.Celui aussi qui brise le silence imposé. Celui enfin qui s'oppose à la violence exercée par l'époux ou le despote.

“- Regardez combien d'alliances j'ai dans cettebourse:quatre-vingt-dix-huit.Savezvous d'où elles viennent?

- Non, nous l'ignorons, firent les deux rois. - Eh bien, ce sont celles des quatre-vingtdix-huit hommes avec lesquels j'ai couché. Et voilà, maintenant ça fait cent ! Cent hommes qui m'ont prise à la barbe de ce djinn répugnant qui ronfle comme une scie à bois, croyant que je n'appartiens qu'à lui. II me garde enfermée dans une caisse au fond de la mer! Mais c'est un imbécile: il ne sait pas que lorsqu'une femme veut quelque chose, personne ne peut l'empêcher de l'obtenir, fût-elle emprisonnée au fond d'une mer déchaînée et surveillée par un démon jaloux." Hanan el-Cheikh rappelle ici que les voix féminines qui résonnent dans cette Maison de Schéhérazade, en invitant à briser la domination ou à s'en jouer, ouvrent aussi une fenêtre sur l'exigence démocratique. M. H. 